\title{
Heart-lung transplantation for cystic fibrosis. 1: Assessment
}

B. Whitehead, P Helms, M Goodwin, I Martin, B Lask, E Serrano, J P Scott, R L Smyth, T W Higenbottam, J Wallwork, $M$ Elliott, $M$ de Leval

\section{Abstract}

Forty five patients with cystic fibrosis (age 515 years) were assessed for heart-lung transplantation between September 1987 and March 1990. The two main conditions for acceptance were (i) life expectancy less than 2 years and (ii) a severely impaired quality of life. Patients were accepted onto an active waiting list $(n=26)$, a provisional waiting list $(n=15)$, or not accepted $(n=4)$.

Selection was made on clinical grounds with objective measurements used as an aid in assessment. As expected, the mean values for objective measures were significantly different between patients on the active waiting list compared with the provisional waiting list/not accepted group for resting heart rate (118/ minute $v 101 /$ minute), percentage of ideal weight $(83.2 \% v 93.1 \%)$, forced expiratory volume at one second as percent of predicted normal (27.3\% $v$ 47.6\%), ShwachmanKulczycki score (33.6 v 52.5), ChrispinNorman $x$ ray score $(25.8 v 22.1), 12$ minute walk (540 m $v 854 \mathrm{~m}$ ), and minimal oxygen saturation (81.5\% $v$ 92\%). Psychological evaluation demonstrated a $55 \%$ incidence of individual and a $50 \%$ incidence of family morbidity.

Of the 26 patients accepted onto the active waiting list, 11 have been transplanted (mean waiting time 3.3 months), 10 have died within a mean of 3.7 months of acceptance, and five remain on the active list (mean 5.6 months).

The Hospital for Sick Children, Great Ormond Street, London B Whitehead P Helms M Goodwin I Martin

B Lask

E Serrano

M Elliott

$M$ de Leval

Papworth Hospital, Papworth Everard, Cambridge

J P Scott

R L Smyth

$T$ W Higenbottom

J Wallwork

Correspondence to:

Dr B Whitehead,

Cardiothoracic Unit,

The Hospital for

Gick Children, Street,

Great Ormond Street,
London WCIN 3JH.

Accepted 8 May 1991
Despite the improving prognosis in cystic fibrosis ${ }^{1}$ there is still an appreciable mortality in the young child and adolescent in the United Kingdom, with a total of 41 deaths between the ages of 1-14 years reported in 1988 (figure). Most deaths were due to respiratory disease and therefore many of these patients may be eligible for heart-lung transplantation. Heart-lung transplantation was first successfully performed in adults with pulmonary vascular disease in $1981^{2}$ and later in those with cystic fibrosis. ${ }^{3}$ Experience of heart-lung transplantation in children is limited, but an early report has shown encouraging results. ${ }^{4}$

Since paediatric referrals for heart-lung transplantation were accepted at our institutes, by far the largest single group has been children with cystic fibrosis (45 of the 64 ). For such a major procedure with an uncertain long term outcome, a condition for acceptance onto our programme has been a life expectancy of less than two years. However, prognostic indicators for

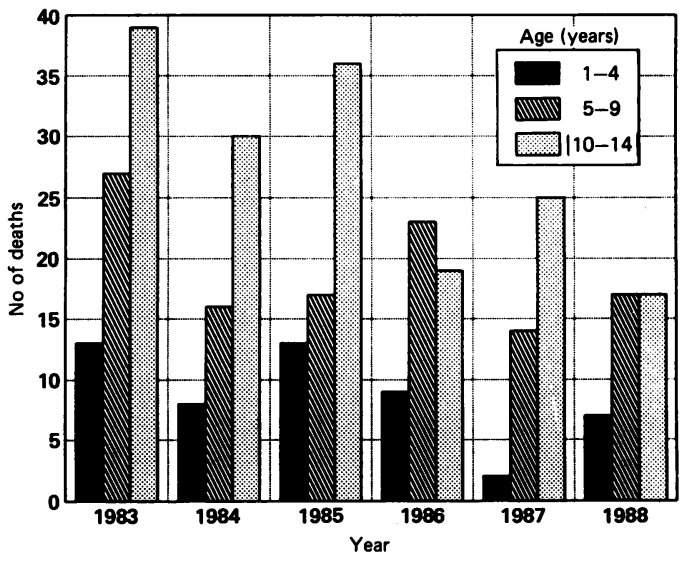

Cystic fibrosis deaths, by age, in the UK for 1983-8 (supplied by the Office of Population Censuses and Surveys for England and Wales, and the Registrar General's Departments of Scotland and Northern Ireland).

short term survival are not available as most reports deal with long term outcome. ${ }^{5-7}$

\section{Patients and methods}

From September 1987 to March 1990, 45 patients with cystic fibrosis were assessed at our institutes for heart-lung transplantation. Ages ranged from 5-15 years (mean 11.3), 25 of whom were girls and 20 boys. Referred patients aged 16 years and above were assessed at our adult centre (Papworth Hospital). Before admission, referring paediatricians were requested to complete a proforma. This helped to identify those unsuitable for transplantation. Absolute contraindications were few but included previous pleurectomy and pleurodesis, advanced liver or renal disease, severe psychosocial disturbance, and high dose steroid treatment $(>1 \mathrm{mg} / \mathrm{kg} / \mathrm{day})$. A pulmonary aspergilloma was an absolute contraindication, although allergic bronchopulmonary aspergillosis or the presence of aspergillus in the sputum were not.

Children were admitted for four to five days with their parents and, whenever possible, their siblings. They were assessed by a multidisciplinary team including carers experienced in cystic fibrosis, social worker, child psychologist and psychiatrist, and both child and family were familiarised with the full implications of heartlung transplantation. Patients and families were also reviewed by a physiotherapist, pharmacist, and dietitian.

Each child underwent a complete clinical assessment including resting heart rate, ${ }^{8}$ per- 
centage of ideal weight corrected for height, ${ }^{9}$ full lung function including plethysmography and spirometry with forced expiratory volume at one second expressed as a percentage of predicted normal $\left(\mathrm{FEV}_{1} \%\right),{ }^{10}$ ShwachmanKulczycki score, ${ }^{11}$ Chrispin-Norman $x$ ray score, ${ }^{12}$ a 12 minute walk, ${ }^{13}$ pulse oximetry (Ohmeda Biox 3700), and assessment of right heart function by electrocardiography and echocardiography. 14

Renal function was assessed by plasma urea and creatinine estimation together with a measurement of glomerular filtration rate (24 hour creatinine clearance or radiolabelled EDTA estimation of glomerular filtration rate). Hepatic function was assessed by liver ultrasonography together with liver function tests and coagulation studies. Liver biopsies were not routinely performed.

Microbiological investigations of sputum and throat and nose swabs were performed in order to ensure appropriate chemoprophylaxis at the time of transplantation. Surveillance for active mycobacterial infection was also performed. Urine was collected for bacterial and viral culture together with serum titres for cytomegalovirus, toxoplasma, hepatitis B surface antigen, HIV, herpes simplex virus, varicella zoster virus, Epstein-Barr virus, rubella and measles viruses. Fungal titres for candida and aspergillus fumigatus were also performed. These provided valuable baseline data for clinical management during postoperative immunosuppression.

Complete dental examination, including radiography, was undertaken to exclude occult infection and any dental caries found was dealt with during or soon after admission.

As well as a formal 12 lead electrocardiography and echocardiography, a 24 hour electrocardiographic tape was taken to assess the suitability of the heart as a possible donor organ (the domino procedure). ${ }^{15}$

Both patient and family underwent extensive psychosocial evaluation by a psychiatrist (BL) and psychologist (ES). This was complemented by informal assessment throughout the admission by the transplant liaison sister (MG).

The child's psychological functioning was determined by his/her mental state (mood, anxiety), coping mechanism, and general adjustment and attitude to illness. Questionnaires and a semistructured psychiatric interview were utilised. Three levels of functioning were determined: level 1 indicated normal functioning, level 2 moderate dysfunction, and level 3 severe dysfunction. ${ }^{16} \mathrm{~A}$ similar rating of functioning of the family as a whole was obtained by observing family interactions, parental subsystem, communication, and problem solving during a clinical interview.

On completion of the inpatient assessment, a combined decision meeting was convened with the family. For younger children (less than 10 years), this was usually confined to the parents, but older children were included if they wished. Patients were either accepted on to an active transplant waiting list indicating they were eligible for transplantation from that time, a provisional waiting list indicating that they were not severely enough affected but would be reassessed at a later date, or not accepted having been assessed as too well.

Children accepted on to the active list underwent further preparation by the ward sister, the transplant liaison sister, the play specialist and/ or school teacher. Logistical arrangements for patient transfer at time of transplantation, including the issuing of a long range radio pager, were organised by the coordinator (IM).

Comparison of clinical measurements of those accepted and on those not accepted to the active waiting list was performed. Statistical analysis was by Student's $t$ test for unpaired data. A p value of less than $\mathbf{0 . 0 5}$ was accepted as significant.

\section{Results}

Of the 45 patients assessed, 26 were accepted on an active waiting list, 15 on a provisional waiting list, and four were not accepted.

Mean (SD) values of heart rate, percentage of ideal weight corrected for height, $\mathrm{FEV}_{1} \%$, minimal oxygen saturation, distance covered in a 12 mintute walk, Shwachman-Kulczycki score and Chrispin-Norman score of the two groups (active waiting list and provisional waiting list/ not accepted group) are shown in table 1. Significant differences were noted when comparing all measurements of these two groups.

Levels of psychosocial functioning of 22 children and families accepted on the active waiting list are shown in table 2. No patients were refused acceptance onto the transplantation programme for psychological reasons, although one patient underwent two months further treatment before being placed onto the active transplant list. The four remaining children at level 3 were referred for further psychological treatment but were not excluded from acceptance on the active waiting list.

Table 1 Mean (SD) values of clinical measurements in patients on active waiting list and provisional waiting list/not accepted group

\begin{tabular}{llll}
\hline Measurement & $\begin{array}{l}\text { Active } \\
\text { waiting list } \\
(n=26)\end{array}$ & $\begin{array}{l}\text { Provisional } \\
\text { waiting list/ } \\
\text { not accepted } \\
(n=19)\end{array}$ & $p$ Value \\
\hline $\begin{array}{l}\text { Heart rate } \\
\text { (beats/minute) }\end{array}$ & $118(14)$ & $101(9)$ & $<0.001$ \\
$\begin{array}{l}\text { Ideal weight } \\
\text { FEV } \%\end{array}$ & $\begin{array}{l}83.2(9 \cdot 7) \\
27.3(10.5)\end{array}$ & $\begin{array}{l}93.1(9.3) \\
47.6(21 \cdot 2)\end{array}$ & $<0.01$ \\
$\begin{array}{l}\text { Shwachman- } \\
\text { Kulczycki score }\end{array}$ & $33.6(4.9)$ & $52.5(7.8)$ & $<0.001$ \\
$\begin{array}{c}\text { Chrispin-Norman } \\
\text { chest x ray score }\end{array}$ & $25.8(2.5)$ & $22.1(3.2)$ & $<0.001$ \\
$\begin{array}{l}\text { 12 Minute walk (m) } \\
\text { Minimal oxygen }\end{array}$ & $540(324)$ & $854(235)$ & $<0.01$ \\
saturation (\%) & $81.5(9.6)$ & $92(3.9)$ & $<0.001$ \\
\hline
\end{tabular}

Comparison between groups by Student's $t$ test (significance level $\mathbf{p}<0.05$ ).

Table 2 Level of psychosocial functioning of 22 individual children and whole families accepted onto the active waiting list for heart-lung transplantation

\begin{tabular}{llll}
\hline & $\begin{array}{l}\text { Level I } \\
\text { (normal } \\
\text { function) }\end{array}$ & $\begin{array}{l}\text { Level 2 } \\
\text { (moderate } \\
\text { dysfunction) }\end{array}$ & $\begin{array}{l}\text { Level 3 } \\
\text { (severe } \\
\text { dysfunction) }\end{array}$ \\
\hline Child $(\mathrm{n}=22)$ & 10 & 7 & 5 \\
Family $(\mathrm{n}=22)$ & 11 & 8 & 3 \\
\hline
\end{tabular}


Only one patient had clinical evidence of severe hepatic involvement associated with portal hypertension. None of the patients assessed showed abnormal renal function. Mean (SD) plasma creatinine concentration was $49 \cdot 4(7 \cdot 35)$ $\mu \mathrm{mol} / \mathrm{l}$. All patients on the active list were negative for cytomegalovirus antibody. This had important implications for donor selection, as we specified cytomegalovirus compatibility in order to avoid the development of life threatening pneumonitis post-transplant. ${ }^{17}$

Of the 26 patients accepted on the active waiting list, 11 were transplanted (mean waiting time 3.3 months), 10 died within a mean of 3.7 months of acceptance, and five remain on the active list (mean 5.6 months).

\section{Discussion}

One of the major difficulties confronting any new transplantation programme is the determination of appropriate and practical selection criteria for recipients. We chose a prognosis of less than two years as the current survival figures for heart-lung transplantation seen in the adult series over this period was $70 \% .^{18}$ The lack of information on short term prognosis in cystic fibrosis therefore compromised this selection criterion.

The selection criteria were supported by the fact that all deaths occurring on the active waiting list were within our prognostic time scale and none of those suriviving on the list untransplanted have so far exceeded this two year period. On the other hand, of the patients on either the provisional waiting list or those not accepted, only one death occurred. This was due to an unexpected viral pneumonia in a 7 year old boy with a baseline ShwachmanKulczycki score of 49 . It is our practice to reassess all patients on the provisional waiting list at intervals of three to 12 months and place them on the active list if continuing clinical deterioration is observed. However, it is likely that a small number of children on the provisional list may die after a sudden unexpected intercurrent illness as occurred in this patient.

We found the most helpful clinical measures in determining short term prognosis, and therefore selection for transplantation, were percentage of ideal weight, FEV $_{1} \%$, ShwachmanKulczycki score, and lowest oxygen saturation obtained obtained during a 12 minute walk. Although it is impossible at present to give absolute 'cut off' parameters, the values shown in table 1 give objective guidelines of severity to referring clinicians when considering transplantation in the deteriorating child with cystic fibrosis. Longer term follow up of survival of those patients assessed may yield more concrete guidelines.

The second part of our selection criteria, namely a severely impaired quality of life, raises further difficulties. Few guidelines are available in the current literature ${ }^{19}$ and the whole topic is plagued by subjective interpretations. By combining both objective clinical measurements and the more subjective quality of life measures, we believe an appropriate decision can be made.

Contraindications to heart-lung transplanta- tion are decreasing in number as further experience is gained. For example, patients with previuos thoracotomy, diabetes mellitus, and those on low dose steroid treatment are now accepted. Those with cirrhosis and portal hypertension may also be eligible for heart, lung, and liver transplantation as experience with this technique increases. ${ }^{20}$ Accordingly, current absolute contraindications may become only relative in the future.

We were fortunate in that patients, and/or families, who would be unsuitable for heartlung transplantation due to psychosocial contraindications, tended not to be referred for assessment in the first instance. However, there remains a relatively high incidence of psychological morbidity in those reaching formal assessment as observed in our population. Indentifying the child and/or family with underlying psychological problems (level of functioning 2 and 3) helps to establish a framework for preparation for transplantation and after care. Together with the added burdens of awaiting transplantation and then of transplantation itself, ${ }^{21}$ it is imperative that a psychosocial support network is mobilised for 'at risk' patients and families.

Dispelling unrealistic expectations and confronting families with the realities of transplantation can be painful, but is an essential part of the assessment. The uncertainties of the waiting period, the immediate postoperative phase, and more importantly the long term issues of rejection, infection, life long drug treatment with its associated side effects, repeated hospitalisation and disruption to the family, must be balanced against the hoped for improved quality of life. The same degree of honesty must be afforded the child, particularly in confronting death, something many parents find difficult to cope with.

At the time of preparation, the total cost of the assessment admission was $£ 1408$. This represented $5 \cdot 4 \%$ of the first year's total cost when transplantation was performed. This cost could be greatly reduced if assessment was managed on an outpatient basis, but we feel this approach would be counterproductive for both the patient and the transplant team.

The outcome of those patients undergoing heart-lung transplantation is discussed in the second part of this review. ${ }^{22}$

Special thanks to Miss P Smith and Miss L Stanger for preparation of the manuscript.

1 Anonymous. Survival in cystic fibrosis. Lancet 1984;i:663-4.

2 Reitz BA Wallwork iL, Hunt SA, et al. Heart-lung transplantation. Successful therapy for patients with pulmonary vascular disease. $N$ Engl f Med 1982;306:557-64.

3 vascular disease. $N$ Engl $f$ Med 1982,306:557-64. transplantation for cystic fibrosis. Lancet 1988;ii: 192-4. Smyth RL, Higenbottam TW, Scott JP, et al. Early exper ence of heart $1225-30$.

5 Knoke JD, Skern RC, Doershuk CF, Boat TF, Matthews LW. Cystic fibrosis: the prognosis for five-year survival. PW. Cystic fibrosis: the progn

6 Huang NN, Schidlow DV, Szatrowski TH, et al. Clinical features, survival rate, and prognostic factors in young features, survival rate, and prognostic factors in youn
adults with cystic fibrosis. Am $\mathcal{J}$ Med 1987;82:871-9. adults with cystic fibrosis. Am $\mathcal{F}$ Med 1987;82:871-9.
Hudson I, Phelan PD. Are sex, age at diagnosis, or mode of Hudson I, Phelan PD. Are sex, age at diagnosis, or mode of
presentation prognostic factors for cystic fibrosis? Pediatr presentation prognostic
Pulmonol 1987;3:288-97.

8 Levy VL, Durie P, Pencharz P, Corey M. Prognostic factors associated with patient survival during nutritional rehabili- 
See related papers on $p 1013$ and 1022 . tation in malnourished children and adolescents with cystic fibrosis. I Pediatr Gastroenterol Nutr 1986;5:97-102.

9 Kraemer R, Rudeberg A, Hadorn B, Rossi E. Relative underweight in cystic fibrosis and its prognostic value. Acta Pediatr Scand 1978;67:33-7.

10 Polgar G, Weng TR. The functional development of the respiratory system from the period of gestation to adultrespiratory system from the period of gestation

11 Shwachman H, Kulczycki LL. Long-term study of one hundred and five patients with cystic fibrosis. Am $\mathcal{F}$ Dis Child 1958;96:6-15

12 Chrispin AR, Norman AP. The systematic evaluation of the chest radiograph in cystic fibrosis. Pediatr Radiol 1974;2: 101-6.

13 McGavin CR, Artvinli M, Naoe H, McHardy GJR. Dyspnoea, disability and distance walked: comparison of estimates of exercise performance in respiratory disease. BMF 1978;ii:241-3.

14 Stern RC, Borkat G, Hirschfeld SS, et al. Heart failure in cystic fibrosis. Treatment and prognosis of cor pulmonale with failure of the right side of the heart. $A m \mathcal{J}$ Dis Child 1980;134:267-72.
15 Merz B. Heart/lung recipient becomes first living heart donor in United States. FAMA 1987;257:3019.

16 Lask B, Jenkins J, Nabarro E, Booth I. The psychological sequelae of stoma surgery in childhood-a controlled follow-up. Gut 1987;28:1257-60.

17 Hutter J, Scott J, Wreghitt T, Higenbottam T, Wallwork J. The importance of cytomegalovirus in heart-lung transThe importance of cytomegalovirus in hear

18 Hutter JA, Despins P, Higenbottam T, Stewart S, Wallwork J. Heart-lung transplantation: better use of resources. $A m$ J. Heart-lung transplanta

19 Bywater EM. Adolescents with cystic fibrosis: psycho-social adjustment. Arch Dis Child. 1981;56:538-43.

20 Wallwork J, Williams R, Calne RM. Transplantation of the liver, heart, and lungs for primary biliary cirrhosis and primary pulmonary hypertension. Lancet 1987;ii:182-5.

21 Gold LM, Kirkpatrick BS, Fricker FJ, Zitelli BJ. Psychosocial issues in paediatric organ transplantation: the social issues in paediatric organ transplantation

22 Whitehead $B$, Helms $P$, Goodwin $M$, et al. Heart-lung trans plantation for cystic fibrosis. 2: Outcome. Arch Dis Child 1991;66:1022-6.

\section{Endotoxin antibody in the treatment of Gram negative septicaemia}

Advances in the understanding of mechanisms of pathogenesis in severe sepsis (see Archivist 1991: 137 and 340) have led to fresh thoughts about possible treatments. A recent paper in the New England fournal of Medicine (Ziegler et al, 1991; 324: 429-36) describes the results of giving human monoclonal antibody against endotoxin to adults with Gram negative bacteraemia and septic shock.

The release of endotoxin into the circulation leads to shock and tissue damage through the intermediary of cytokines. The destruction of endotoxin might therefore be expected to be beneficial. Previous trials showing a protective effect have involved the use of polyclonal antisera produced in human volunteers. Monoclonal IgM antibody (HA-1A) is produced from myeloma cell cultures. It is more specific, binding to the lipid A domain of the lipopolysaccharide endotoxin, and its use avoids the need to immunise volunteers and the dangers of using pooled human blood.

The trial was performed at 24 academic medical centres in the United States, Canada, and Europe. All the patients were severely ill with septic shock defined on clinical grounds.

A total of 543 patients entered the trial and were randomly assigned to receive either HA-1A or placebo (human albumin). Two hundred patients proved to have Gram negative bacteraemia on blood culture and the analysis of the trial results is confined to this 200, 105 of whom received HA-1A and 95 placebo.

Overall mortality was reduced from $50 \%$ in the placebo group to $30 \%$ in the treatment group. Benefit was seen both in those very severely ill (severe shock and high APACHE score) and in those less severely ill. No serious adverse reactions to the treatment were encountered.

This trial on adults has important implications in paediatrics. Neisseria meningitidis is a potent producer of endotoxin and antibody against lipid $\mathrm{A}$ should be effective in meningococcal septicaemia. A multicentre trial of HA-1A in meningococcal septicaemia in children has recently started. The results will be awaited with great interest. 